AIAA 80-1242R

Cooling Air Inlet and Exit Geometries

on Aircraft Engine Installations

J. Katz, V.R. Corsiglia, P.R. Barlow

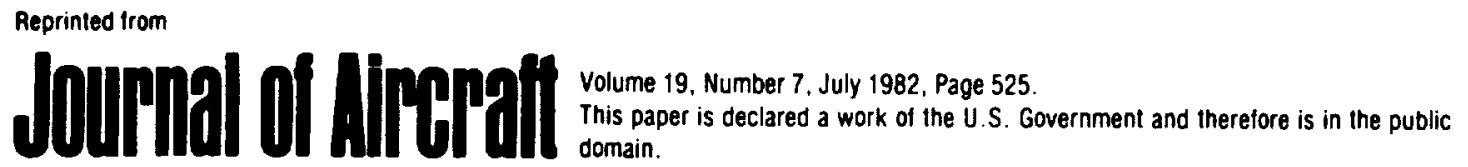




\title{
Cooling Air Inlet and Exit Geometries on Aircraft Engine Installations
}

\author{
Joseph Katz, * Victor R. Corsiglia, $\dagger$ and Philip R. Barlow $\ddagger$ \\ NASA Ames Research Center, Moffett Field, Calif.
}

\begin{abstract}
A semispan wing and nacelle of a typical general aviation Iwin-engine aircraft was tested to evaluate the cooling capability and drag of several nacelle shapes; the nacelle shapes included cooling air inlet and exit variations. The lests were conducled in the Ames Research Center $40 \times 80-\mathrm{ft}$ Wind Tunnel. It was found that the cooling air inlet geometry of opposed piston engine installations has a major effect on inlet pressure recovery, but only a minor effect on drag. Exit location showed a large effect on drag, especially for those locations on the sides of the nacelle where the suction characteristics were based on interaction with the wing surface pressures.
\end{abstract}

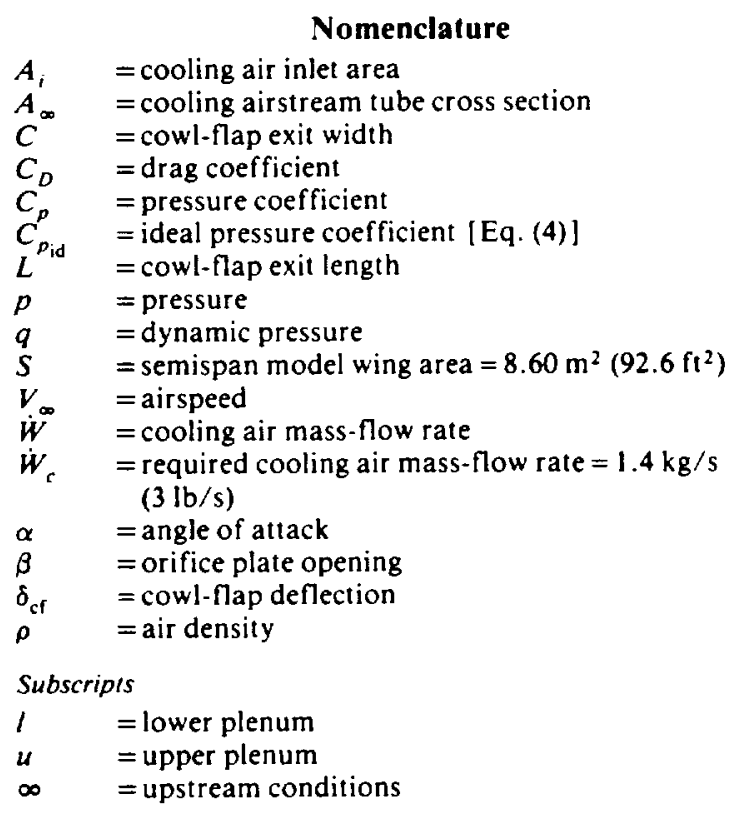

\section{Introduction}

THE airborne piston engine cooling problem is almost as old as powered flight itself. During World War II, there were numerous studies of engine cooling and nacelle installations. A summary of the British effort at that time is given in Ref. 1. The combined study of engine cooling and associated nacelle drag (cooling drag) was initiated only recently, ${ }^{2.5}$ because of difficulties in availability and increases in the price of fuel. The present opposed piston layout used on general aviation aircraft led to new cooling problems that are different from those of earlier radial engine installations. An early study of such horizontally opposed installations is reported by Ellerbrock and Wilson, ${ }^{6}$ who started with cooling air inlets located on both sides of the spinner, similar to present design practice. By combining a single low inlet (under

Presented as Paper 80-1242 at the AIAA/SAE/ASME 16th Join Propulsion Conference, Hartford, Conn., June 30-July 2, 1980 submitted Aug. 22, 1980; revision received July 6, 1981. This paper is declared a work of the U.S. Government and therefore is in the public domain.

-NRC Associate; presently, Professor, Mechanical Engineering Department, Technion, Haifa, Israel.

†Aerospace Engineer. Member AiAA.

†Aerospace Engineer. the spinner) with an upflow cooling system, however, they considerably improved the cooling characteristics of the installation. Current experience with piston engine installations is summarized by Monts. ${ }^{2}$ Miley et al. ${ }^{3.4}$ recently conducted a series of flight tests in which they recorded inlet pressure recovery data to obtain inlet efficiency, propeller slipstream, total pressure, and the pressure drop across the cylinders for several inlet geometries. The major concern of their studies was the engine cooling; drag data were secondary considerations. In order to fill this need, accurate measurements of nacelle drag were conducted in the $40 \times 80-\mathrm{ft}$ Wind Tunnel at Ames Research Center by Corsiglia et al.," who found that about $13 \%$ of the aircraft drag is associated with the cooling requirements of the engines. Only $2-4 \%$ of the airplane drag results from the engine itself. The balance is associated with inlet losses and the external shape, including the cowl flap (Fig. 1). The present study, a continuation of that investigation, examines the pressure recovery and relative drag of several cooling air inlets; the performance and drag effects of various air exits were also tested and analyzed.

\section{Experimental Setup}

In the present test, a semispan wing model of a typical general aviation twin-engine aircraft was mounted vertically in the Ames $40 \times 80-\mathrm{ft}$ Wind Tunnel (Fig. 2). The production nacelle that was tested had two side inlets and one cowl-flap exit at the bottom. During the test, both the size and shape of the cooling air inlets and exits were changed. The drag and lift forces were measured, using the wind-tunnel scales. In addition, the pressure was recorded at 48 locations in and around the nacelle.

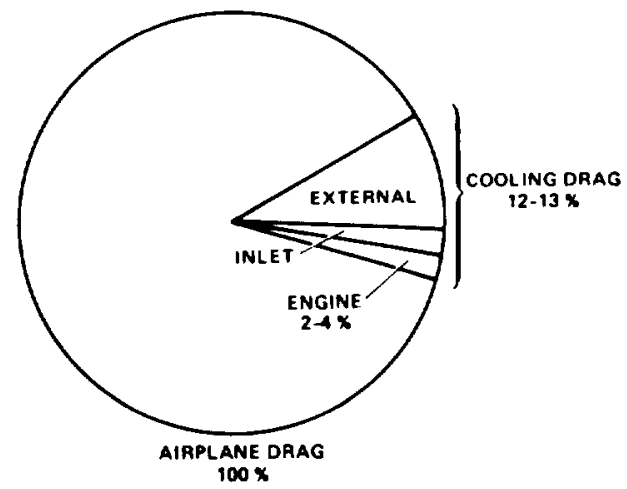

Fig. 1 Magnilude of cooling drag relative to airplane drag and magnitude of various components of cooling drag. 


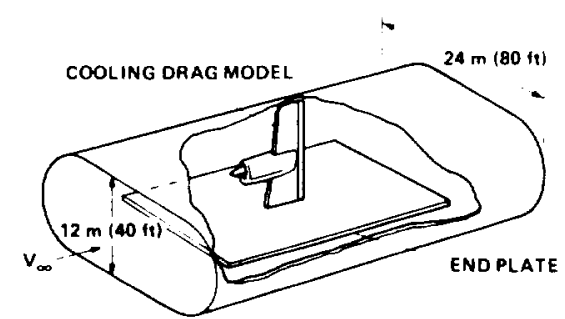

Fig. 2 Schematic of cooling drag model in the $40 \times 80-\mathrm{ft}$ Wind Tunnel.

COOLING AIR INLET ENGINE SIMULATOR

a)
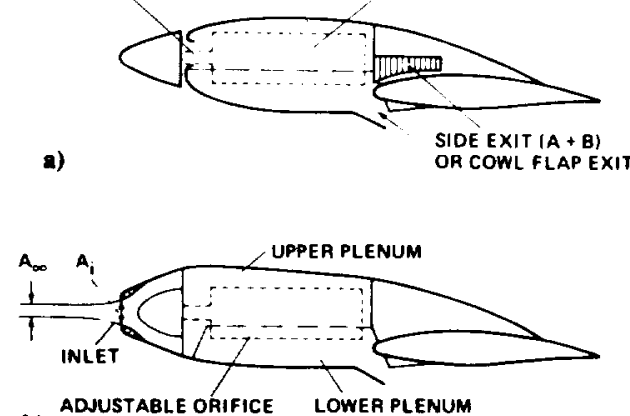

b) ODIUNTABGS

Fig. 3 Schematic of airflow through cooling drag model. a) Production nacelle; b) spinner inlet.

A schematic description of the cooling drag model is given in Fig. 3. The cooling air entered through the inlet into the upper plenum, where the recovery pressure was measured; it then passed through an adjustable orifice plate into the lower plenum. By varying the orifice opening, the cooling air massflow rate was controlled. From the lower plenum the air was exhausted through the exit, which was either on the sides or on the bottom of the nacelle. Only the bottom exit (Fig. 3a) was assisted by a cowl flap. The total pressure recovery in the upper plenum was measured by eight total pressure probes (Kiel) and four static holes. The total pressure in the lower plenum was measured in a similar manner, but only four Kiel probes were used. The total pressures at the exits were measured by four Kiel probes and the static pressures by four static holes on the outside of the nacelle. Additional surface pressure data on the back of the nacelle were recorded through static holes on the surface.

An engine simulator was fitted in the middle of the nacelle (Fig. 3) for the wind-tunnel runs. It consisted of a tubular volume that partially filled the upper and lower plenum volumes, thereby using space normally occupied by a gasoline engine. Further details on the test apparatus and cooling air mass-flow measurements are given in Ref. 5 . The accuracy of lift and drag data was about 0.1 and $1.0 \%$, respectively.

Two basic flight conditions, climb and cruise, were examined during the test. Table 1 defines these two flight conditions. The air mass-flow rate through the nacelle for each configuration was increased by opening the orifice plate from $\beta=0$ to the fully open $\beta=1.0$ position. The reduction in the inlet size was obtained by inserts (Fig. 4) that had smaller openings but retained the same inlet contour and inlet lip radius. The production inlet areas are given in Table 1 .

\section{Study of Inlet Geometry}

In this section, two parameters are reported: 1) the cooling air inlet area $\boldsymbol{A}_{i}$ (or velocity ratio) and 2 ) the variation in inlet design. The upper plenum total pressure recovery $C_{p_{u}}$ and semispan model drag coefficient $C_{D}$ are defined as

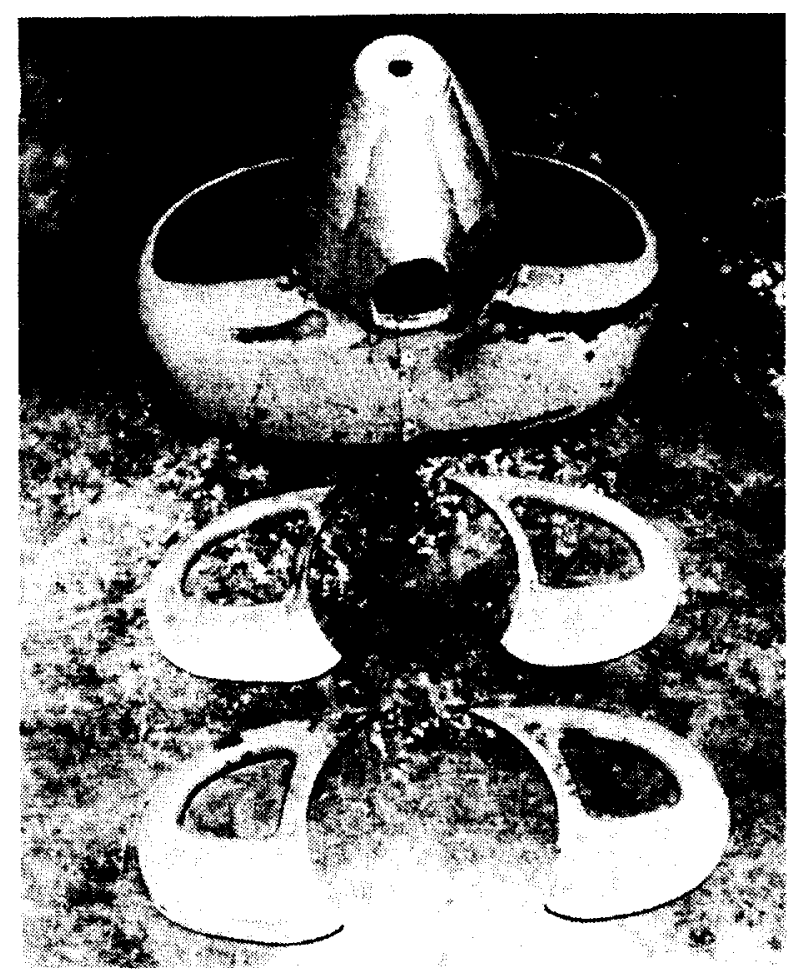

a)

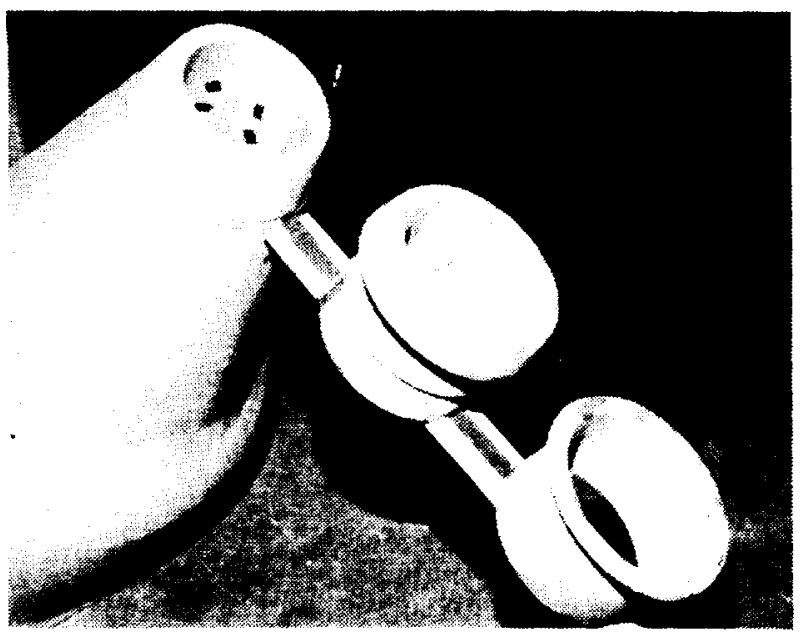

b)

Fig. 4 Inlet inserts used to change inlet area ratio. a) Production inlet; b) spinner inlet.

Table 1 Test variables

\begin{tabular}{lcccc}
\hline \hline \multirow{6}{*}{ Tunnel and model conditions } \\
Condition & $q, \mathrm{~cm} \mathrm{H} \mathrm{H}_{2} \mathrm{O}(\mathrm{ps})$ & $\alpha$, deg & $\delta_{c f}, \mathrm{deg}$ & $v_{\text {oo }}, \mathrm{m} / \mathrm{s}(\mathrm{ft} / \mathrm{s})$ \\
\hline Climb & $15.1(30)$ & 8 & 30 & $50(166)$ \\
Cruise & $40.3(80)$ & 2.3 & 0 & $84(272)$
\end{tabular}

Inlet variables

Production inlet area, Spinner inlet area

$\begin{array}{llc}\text { Inlet } & \begin{array}{c}\mathrm{cm}^{2}\left(\text { in. }{ }^{2}\right) \\ \text { Large }\end{array} & \begin{array}{c}\text { Spinner inlet area, } \\ \mathrm{cm}^{2}(\text { in. }\end{array}\end{array}$



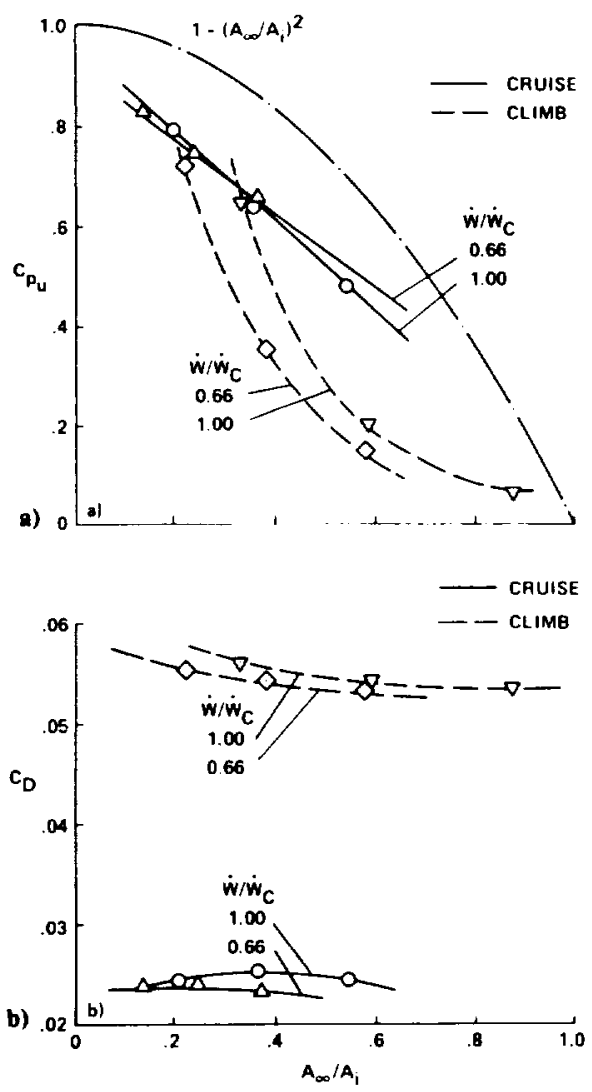

Fig. 5 Influence of cooling air inlet area ratio on a) pressure recovery and b) drag; $\dot{W}_{c}=1.36 \mathrm{~kg} / \mathrm{s}(3 \mathrm{lb} / \mathrm{s})$, production inlet.

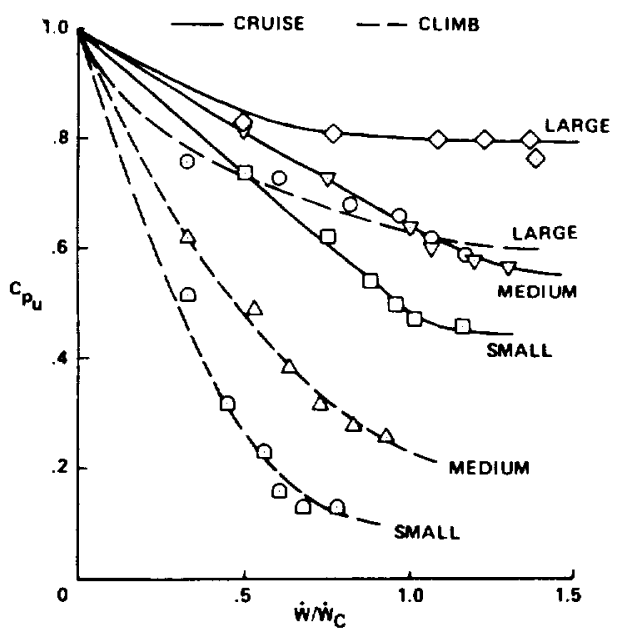

Fig. 6 Pressure recovery of production inlet.

follows:

$$
\begin{gathered}
C_{p_{u}}=\left(p_{u}-p_{\infty}\right) / q \\
C_{D}=D / q S \\
q=\rho_{\infty} V_{\alpha}^{2} / 2
\end{gathered}
$$

Here $p_{u}$ and $p_{\infty}$ are the upper plenum total and far-field static pressures, respectively.

\section{Production Inlet}

The variation of $C_{p_{u}}$ and $C_{D}$ with area ratio is shown in Fig. 5 for a typical production inlet design; the far-field area $A_{\infty}$ represents the area of incoming stream tube, with a uniform velocity $V_{\infty}$ (see Fig. 3). The pressure recovery $C_{p_{u}}$ decreases for decreasing inlet area $A_{i}$ and is smaller than the ideal external pressure recovery $C_{p_{\text {id }}}$ that would be expected ahead of the inlet.

$$
C_{p_{\text {id }}}=l-\left(A_{\infty} / A_{i}\right)^{2}
$$

The value of $1-\left(A_{\infty} / A_{i}\right)^{2}$ is plotted in Fig. 5a; the poorer measured pressure recovery is due to a smaller effective inlet area than the actual geometrical inlet size. This inlet blockage results from the sharp inlet lips and edges and the boundary layer originating from the propeller spinner. The production inlet pressure recovery $C_{p_{u}}$ vs normalized cooling air massflow rate $\dot{W} / \dot{W}_{c}$ is plotted in Fig. 6 , where $\dot{W}_{c}$ is the cooling air mass-flow rate required for adequate cooling at climb. The high inlet losses are due to the inlet design that has no internal diffuser walls to insure high internal pressure recovery. This is so because of the lack of space between the propeller and the engine cylinders. Miley et al. ${ }^{4}$ noted this and studied inlets where the internal diffuser length was increased to the maximum space available. In the absence of internal inlet diffuser length for the production inlet design, higher pressure recoveries can be obtained by increasing the inlet area $A_{i}$, which results in external diffusion, as seen in Fig. 5a.

An earlier study by Becker' that related inlet size to nacelle drag concluded that smaller inlets have lower drag because the transition to turbulent boundary layer is delayed. Becker recommended that inlets have area ratios greater than $A_{\infty} / A_{i}=0.3$ because suction pressure peaks (as shown in Ref. 5) result in a thickened boundary layer and increased drag. Hammen and Rowley ${ }^{8}$ claimed later that reasonable area ratios would be $A_{\infty} / A_{i}=0.4$ for cruise and about 0.8 for the more critical climb condition. The drag coefficient data of Fig. 5b show no significant drag reduction with increasing area ratio. Tuft studies indicate flow separation behind the nacelle and on the wing fairings around the back of the nacelle; the separations were probably initiated by the blunt shape of the nacelle at the inlet section. Therefore changing the size of the inlet did not considerably change the pressure distribution either in the front or in the rear of the nacelle - thus there was almost no change in drag.

Because of the absence of internal diffusion, it is concluded that the performance of production type inlets decreases with reduced inlet size and with increased angle of attack. Therefore, to obtain the highest pressure recovery, the largest inlet is preferred.

\section{Spinner Inlet}

Earlier studies conducted at Ames Research Center ${ }^{5}$ found a nacelle shape with reduced external drag; a flow-through version of the same shape was tested in the present investigation. A schematic description of this configuration (spinner inlet) is shown in Fig. 3. The single inlet forms an annulus around the propeller spinner. Although it did not rotate in the present study, it would, in practice, rotate with the propeller spinner and might have fan blades to extract power from the engine to boost cooling performance. A similar design was tested on an aircraft by Bierman and Turner ${ }^{9}$ in the early days of World War II. They found improved cooling potential with that design when the airplane was on the ground. A further advantage of this layout is the inclusion of a diffuser without using propeller shaft extensions or an increase in upper plenum volume to produce a more uniform cooling air distribution among the cylinders. The performance of such an engine nacelle is given in Figs. 7 and 8; inlet area values are given in Table 1 . In comparison 

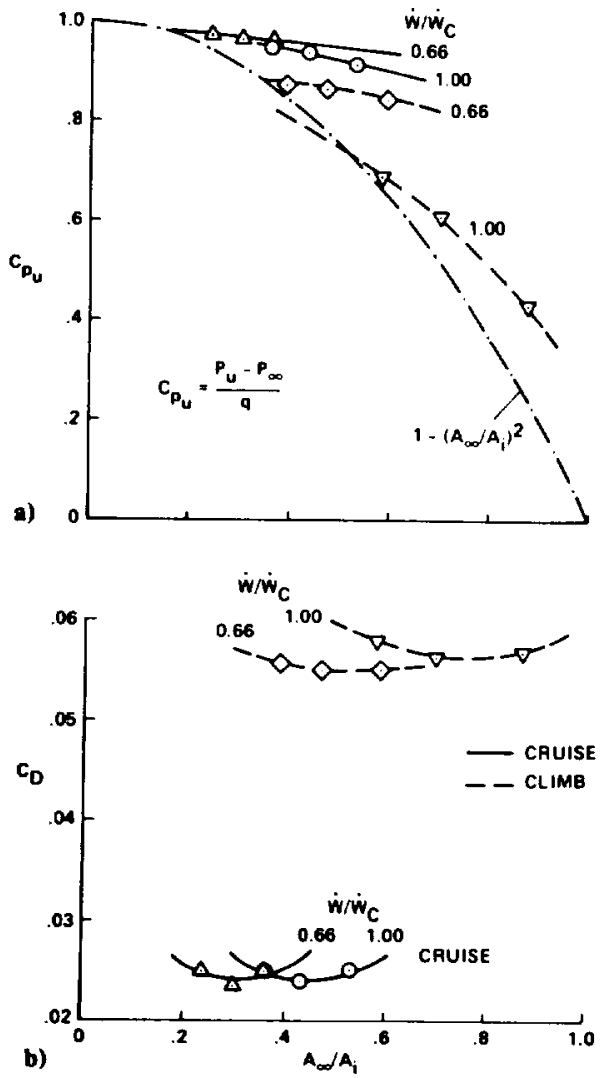

Fig. 7 Influence of cooling air inlet area ratio on a) pressure recovery and b) drag: $\dot{W}_{c}=1.36 \mathrm{~kg} / \mathrm{s}(3 \mathrm{lb} / \mathrm{s})$, spinner inlet.

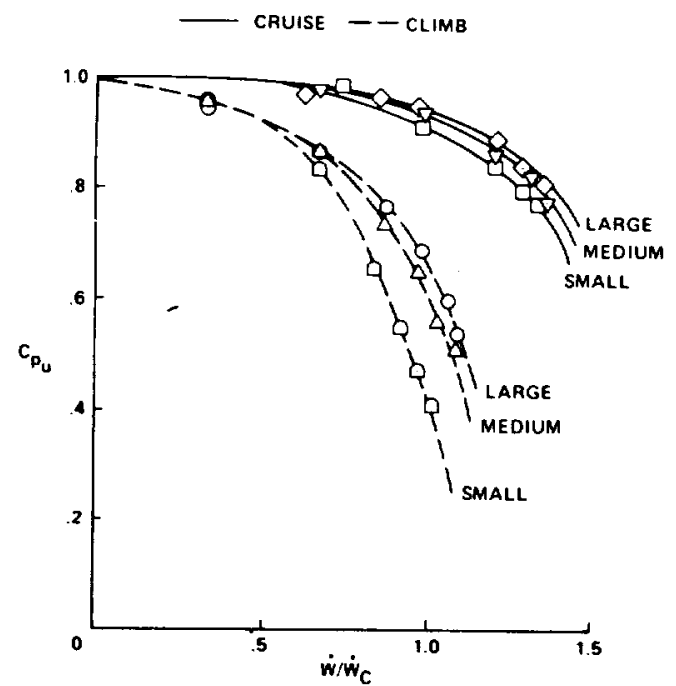

Fig. 8 Pressure recovery of spinner inlet: $\dot{W}_{\mathrm{c}}=1.36 \mathrm{~kg} / \mathrm{s}(3 \mathrm{lb} / \mathrm{s})$.

with the results for a conventional inlet in Fig. 5 , it is evident that the pressure recovery of the spinner inlet is considerably higher and that drag levels are the same. The lack of drag reduction is probably due to the small inlet radius used -1.9 $\mathrm{cm}(0.75$ in.)-to keep the interchangeable inlet duct size small. A larger inlet radius will reduce pressure peaks at the outer side of the inlet lips, thereby reducing the boundarylayer thickness so as to lower the external drag.' For the climb case (Fig. 7a), inlet pressure recovery $C_{p_{u}}$ is much lower as a result of the internal flow separation. All data points are

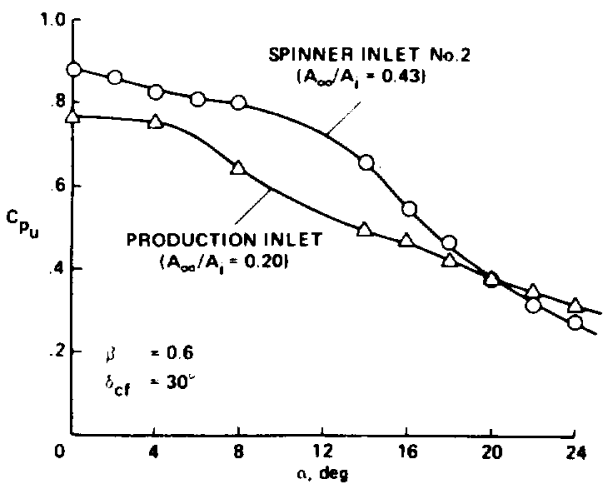

Fig. 9 Inlel pressure recovery vs angle of altack.

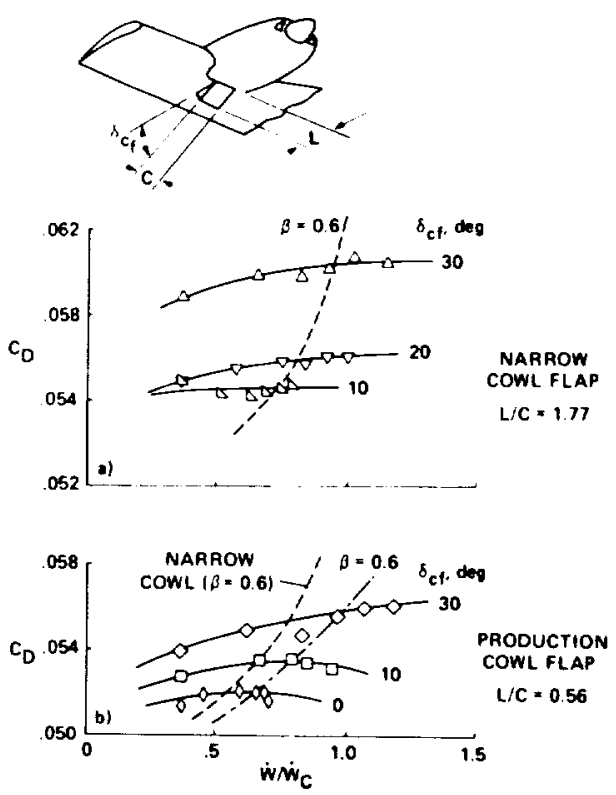

Fig. 10 Drag coefficient of model with cowl-flap exits vs cooling air mass-flow rate; climb configuration. a) Narrow cowl flap, $L=43 \mathrm{~cm}$ (16.9 in.), $C=25 \mathrm{~cm}(9.8 \mathrm{in}$.$) ; b) production cowl flap, L=25 \mathrm{~cm}(9.8$ in.), $C=43 \mathrm{~cm}$ (16.9 in.).

above the external pressure recovery $C_{p j}$, however, indicating that the pressure recovery is greater than that for external diffusion only. Moreover, the cruise data points show internal pressure recoveries of $90-95 \%$, values that are reasonable for such geometry. ${ }^{10}$ Figure 8 also shows the high pressure recovery potential of the spinner inlet geometry. For the climb case $(\alpha=8 \mathrm{deg})$, the inner flow separations are stronger; however, the inclusion of built-in compressor blades on a rotating version of the spinner inlet and a larger inlet lip radius would be expected to significantly improve the pressure recovery. It is interesting to observe the curves in Figs. 6 and 8; they indicate a nonlinear relationship between $C_{p_{u}}$ and mass-flow rate, especially for the climb condition in which internal flow separation is present.

The angle-of-attack-dependent performance of the conventional and spinner inlets is presented in Fig. 9. The conventional inlet had an area ratio of $\boldsymbol{A}_{\infty} / \boldsymbol{A}_{1}=0.2$; the spinner inlet had less than $50 \%$ of this inlet area $\left(A_{\infty} / A_{i}=0.43\right)$. The smaller spinner inlet was used here for the comparison because the pressure recovery is the closest to the conventional inlet. Even so, the drop in $C_{p_{u}}$ starts at angles of attack of about $\alpha=10$ deg instead of at $\alpha=4$ deg for the conventional inlet (orifice opening was the same for both cases, $\beta=0.60$ ). 


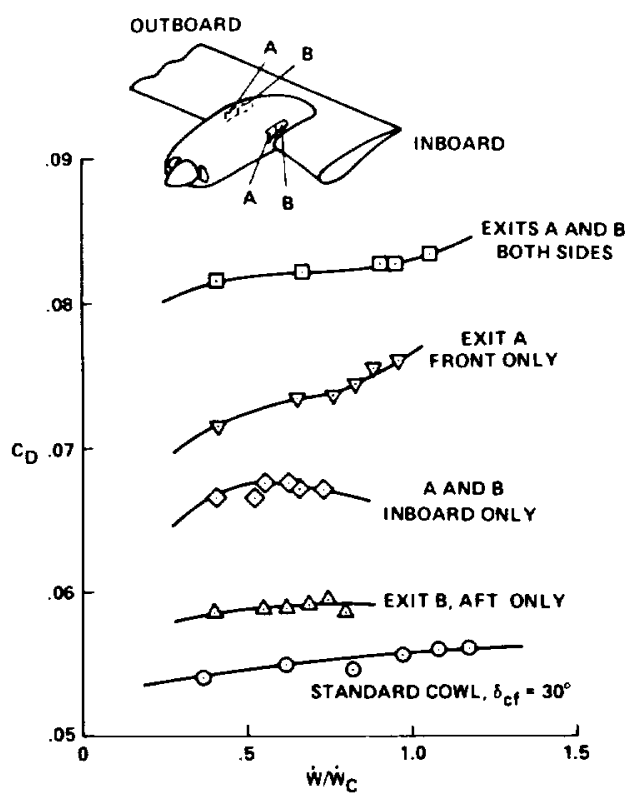

Fig. 11 Drag coefficient of model vs cooling air mass-flow rate with side exits; climb configuration.

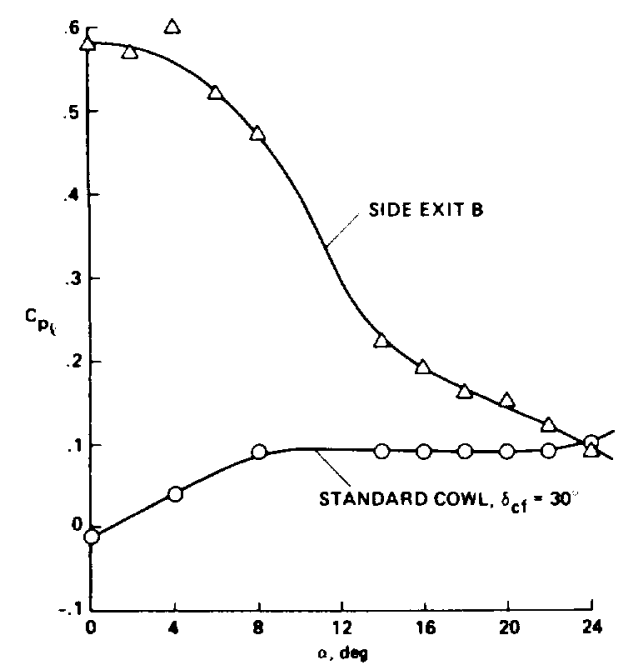

Fig. 12 Lower plenum total pressure variation with angle of attack for side exil B and production cowl flap; climb configuration.

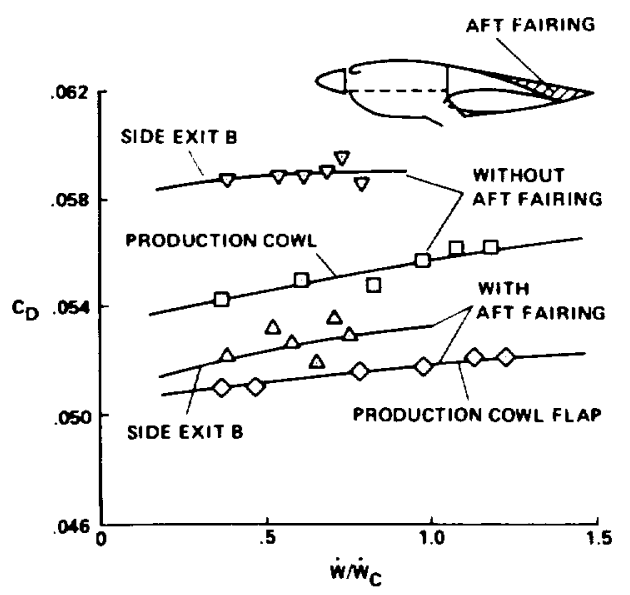

Fig. 13 Effect of aft fairing on nacelle drag for side exil $B$ and production cowl-flap exit $\left(\delta_{\mathrm{cf}}=30 \mathrm{deg}\right)$; climb configuration.
Both inlets show decreased inlet recoveries with increasing angle of attack because of the mentioned internal separations with increased cooling airflow.

\section{Study of Exit Geometry}

\section{Cowl-Flap Exits}

In this section the performances of lower cowl-flap exits (see insert in Fig. 10) and side-mounted exits (insert in Fig. 11) are examined. The problem of cowl-flap exit shape was investigated earlier by Hammer and Rowley, ${ }^{8}$ who found that the longer and narrower cowl flaps provide more efficient pumping of the cooling air. Those exits were mounted on the sides of the aircraft fuselage, however, and no drag data were reported.

Figure 10 shows the drag coefficient due to cowl-flap opening $\delta_{\text {cf }}$ of two exits having the same area. The results for the production cowl are noted to confirm those obtained earlier by Corsiglia et al. ${ }^{5}$ The dimensions of the narrow cowl are the same as those of the production cowl, but the dimensions $L$ and $C$ are inverted. The dashed lines in Fig. 10a, marked by $\beta=0.6$, correspond to data taken at constant orifice opening. This condition was found 10 provide a pressure drop between the upper and lower plenum corresponding to that of an actual gasoline engine. Therefore this line provides the drag variation and cooling air mass-flow rates vs cowl-flap opening $\left(\delta_{\mathrm{cf}}\right)$ as would be measured with an actual gasoline engine present. In Fig. $10 \mathrm{~b}$, the $\beta=0.6$ line of the narrower cowl flap was repeated for comparison with the performance of the wider design. It is evident from that comparison that the narrow cowl flap has both slightly higher drag and lower mass-flow rate (less suction) than the production cowl. A possible explanation for that increase in drag is the stronger vortices that occur on the edge of the separated flow region shed behind the narrow cowl flap due to its greater extension into the airstream.

\section{Side Exits}

The nacelle surface pressure data provided in Ref. S suggested a side location for the cooling exits that might take advantage of the low pressure provided by the wing leading edge (up to $C_{p}=-1.2$ ). ${ }^{5}$ The side exits tested (see Fig. 3 and the insert in Fig. 11) started at $2.5 \mathrm{~cm}$ ( 1 in.) above the wing leading edge and had a total length of $46 \mathrm{~cm}$ (18 in., inlets $A$ and $B)$. Part of the inlet could be closed to provide a forward inlet $A$, having an area of $368 \mathrm{~cm}^{2}\left(57\right.$ in. $\left.{ }^{2}\right)$, or a rear exit section $B$ with an area of $206 \mathrm{~cm}^{2}\left(32 \mathrm{in.}{ }^{2}\right)$. The interaction of the exiting flow with the wing surface pressures resulted in a loss in lift compared to the standard cowl configuration of up to $\Delta C_{L}=0.1$ for $\alpha=8 \mathrm{deg}$. In addition, the drag was increased by the amounts shown in Fig. 11. The configuration $A$ and $B$ inboard only refers to a configuration with exit only on the wing-root side of the nacelle. The aft location of the side exit (configuration $B$ ) in which the external surface pressure coefficient was $C_{p}=-0.8$ (as shown in Ref. 5) seemed to provide improved performance. Lift losses for this configuration (not shown) were less than $\Delta C_{L}=0.05$, and the drag values shown in Fig. 11 are much lower than the drag of the exits, including the $A$ location. The flow-rate values, however, are lower than those with configuration $A$ for corresponding values of the orifice opening $(\beta)$. This is a result of the lower external pressure at this exit location. Preliminary analysis of some more recent data suggests that further improvements in exit performance can be obtained by moving the exit forward of the leading edge.

An important feature of the side exits is seen in Fig. 12. Here the orifice plate opening $\beta$ (simulating the cooling air pressure drop across the cylinders) was set up to $\beta=0.60$. As the wing angle of attack was increased, the suction capability of the side exits increased while that of the production cowl stayed the same. This is an important feature because reduction in aircraft speed results in an increase of angle of 
attack, which corresponds, in the case of climb, to higher cooling airflow requirements. This exit suction characteristic, however, was accompanied by an adverse effect on lift and drag at fixed angle of attack. The interference was partially in the form of increased flow separation on the aft portion of the nacelle as noted by tuft studies. The effect of this flow separation is demonstrated in Fig. 13. Here an aft fairing was added (see insert, Fig. 13) to better contour the surface. It can be seen that the drag is substantially reduced with the aft fairing. In fact, there is a negligible difference in drag between the configuration with side exits with aft fairing and the configuration with cowl-flap exit (e.g., compare Figs. 11 and 13).

It is concluded that the side exits have some very important characteristics, and that by reducing interference with the wing (possibly by a more forward exit location) and modifying the nacelle aft section (aft fairing), they might be an attractive replacement for the present cowl-flap exits.

\section{Conclusions}

It was shown earlier that the cooling drag for a typical general aviation aircraft accounts for as much as $13 \%$ of the aircraft's total calculated drag, and that the power required for engine cooling adds up to only about $2-4 \%$ of the aircraft's drag. That situation can be improved by using inlet designs that provide higher pressure recovery and by using improved cooling exits integrated into a lower drag nacelle. By adding a diffuser to the inlet, pressure recoveries of up to $95 \%$ were demonstrated. That improvement alone can eliminate most of the need for a cowl flap and thereby save up to $3 \%$ of total aircraft drag. Drag reduction by improved nacelle design can be attained by carefully contouring the nacelle aft section. The high drag is mainly a result of the current blunt shape and sharp corners of the front of the nacelle, which cause an increase in boundary-layer thickness that results in flow separation around the inlet and behind the nacelle.

The present study has been extended to include tests with a propeller and tests with an operating piston engine. ${ }^{11,12}$ It was found that the effect of the propeller slipstream was to reduce the frontal air spillage around the blunt nacelle shape. These effects are more pronounced for the climb condition. For the cruise condition, those effects were more moderate.

\section{References}

'Hartshorn, A.S. and Nicholson, L.F., "The Aerodynamics of the Cooling of Aircraft Reciprocating Engines," ARC R\&M 2498, 1956.

${ }^{2}$ Monts, F., "The Development of Reciprocating Engine Installation Data for General Aviation Aircraft," SAE Paper 730325, April 1975.

${ }^{3}$ Miley, S.J., Cross, E.J. Jr., and Owens, J.K., "An Investigation of the Aerodynamics and Cooling of a Horizontally Opposed Engine Installation," SAE Paper 770467, March-April 1977.

${ }^{4}$ Miley, S.J., Cross, E.J. Jr., Lawrence, D.L., and Owens, J.K., "Aerodynamics of Horizontally Opposed Aircraft Engine Installation," AIAA Paper 77-1249, 1977.

${ }^{5}$ Corsiglia, V.R., Katz, J., and Kroeger, R.A., "Full Scale Wind Tunnel Study of Nacelle Shape on Cooling Drag," Journal of Air. craft, Vol. 18, Feb. 1981, pp. 82-88; see also, AIAA Paper 79-1820, 1979.

${ }^{6}$ Ellerbrock, H.H. Jr. and Wilson, H.A. Jr., "Cowling and Cooling Tests of a Fleetwings Model 33 Airplane in Flight," NACA WR-L-632, 1940

'Becker, J.V., "Wind Tunnel Tests of Air Inlet and Outlet Openings on a Streamline Body," NACA WR-L-300, Nov. 1940.

${ }^{8}$ Hammen, T.F. Jr. and Rowley, W.H., "Factors Pertaining to Installation of Internal In-Line Aircooled Aircraft Engines," $S A E$ Journal, Vol. 54, March 1946, pp. 130-152.

${ }^{9}$ Bierman, D. and Turner, L.I. Jr., "Ground Cooling and Flight Tests of an Airplane Equipped with a Nose-Blower Engine Cowling." NACA WR-L-478, Oct. 1939.

${ }^{10}$ Sovran, G. and Klomp, E.D., "Experimentally Determined Optimum Geometries for Rectilinear Diffusers with Rectangular Conical or Annular Cross-Section," Fluid Mechanics of Internal Flow, Elsevier Publishing Co., New York, 1967, pp. 270-319.

I"Katz, J., Corsiglia, V.R., and Barlow, P. " Effect of Propeller on the Drag and Performance of the Cooling System in a General Aviation Twin Engine Aircraft," AIAA Paper 80-1872, Aug. 1980.

${ }^{12}$ Corsiglia, V.R. and Katz, J., "Full-Scale Study of the Cooling System Aerodynamics of an Operating Piston Engine Installed in a Light Aircraft Wing Panel," SAE Paper 810623, April 1981. 